Article

\title{
Screening of Spontaneous Ignition Feasibility During Air Injection EOR Process Based on Thermal Experiments
}

\author{
Siyuan Huang ${ }^{1, *}$, James J. Sheng ${ }^{1,2}$, Qi Jiang ${ }^{1}$ and Jiali Liu ${ }^{1}$ \\ 1 Petroleum Engineering Department, Southwest Petroleum University, Chengdu 610500, China; \\ james.sheng@ttu.edu (J.J.S.); qijiang@shaw.ca (Q.J.); 201811000132@stu.swpu.edu.cn (J.L.) \\ 2 Bob L. Herd Department of Petroleum Engineering, Texas Tech University, Lubbock, TX 79409, USA \\ * Correspondence: huangsiy2013@163.com; Tel.: +86-17308177663
}

Received: 23 August 2019; Accepted: 24 September 2019; Published: 26 September 2019

\begin{abstract}
The feasibility of spontaneous ignition is extremely important to the success of AIP (air injection process) projects. However, no laboratory experiments were reported on the detection of crude oil spontaneous ignition during AIP. The initial intention of the thermal experiments is to screen candidate oil reservoirs for the application of AIP in a faster and less expensive way than combustion tube tests. However, instead of performing a feasibility study, most of the research only employed thermal experiments as a tool to obtain kinetic data and to characterize the thermal-oxidative behavior for different crude oil samples. The question of how to use the thermal experiments to determine the feasibility of spontaneous ignition has not been answered yet. This study proposes a practical method to investigate the spontaneous ignition feasibility during AIP, which directly relates the oil reactivity and reservoir properties. An example of the application of this method was presented in this paper, where a mixture of a light oil and sand was tested by the TGA and DSC to obtain the kinetic data and net heat. The obtained parameters were then used to evaluate the feasibility of spontaneous ignition. The results showed that the tested oil and sand mixture cannot lead to spontaneous ignition due to crude oil's insufficient reactivity. Furthermore, the typical crude oil kinetic data and reservoir conditions were used to investigate the screening criteria for spontaneous ignition. The results indicated that the crude oil's activation energy and frequency factor need to be less than $60 \mathrm{~kJ} / \mathrm{mole}$ and higher than $2 \mathrm{~s}^{-1}$, respectively, in order to satisfy the need of spontaneous ignition.
\end{abstract}

Keywords: air injection; enhanced oil recovery; spontaneous ignition; TGA/DSC; crude oil

\section{Introduction}

Thermal recovery is a major branch of EOR (enhanced oil recovery) processes. Among various thermal recovery methods, AIP (air injection process) technology is a technology used to recover crude oil from a reservoir by generating thermal energy in the reservoir. Depending on the reservoir type, AIP can be divided into two categories: ISC (in-situ combustion) and HPAI (high pressure air injection), where the ISC method is commonly practiced in a heavy oil reservoir, and the HPAI method is often used in a light oil reservoir. The main difference between the HPAI and ISC is that the ISC requires an artificial ignition technique to build the combustion front, while the HPAI is designed to meet the spontaneous ignition criteria. The application of AIP in light oil reservoirs has gained great success in the North and South Dakota portions of the Williston basin, which was started in 1979 and continues to be a technical and economic success. The success was mainly attributed to the thermal effects based on the combustion front propagation. Kumar et al. [1] stated that more than half of the cumulative oil production was contributed to by the thermal effects for the HPAI project in the 
West Buffalo Red River Unit. Furthermore, it was reported that many of the wells did not exhibit a typical exponential increase in GOR but a flat and constant GOR, which indicates the characteristics of combustion fronts propagation [2]. Other than that, spontaneous ignition was observed in the field air injection research project in the South Belridge field, Calif. The test pattern was a single 2.5-acre five spot pattern in $700 \mathrm{ft}$. deep sand. The result indicates that the combustion was achieved spontaneously, and the entire injection wellbore temperature exceeded $537^{\circ} \mathrm{C}$ [3]. The high recovery performance of the combustion front is described as the "bulldozing effect" [4]. It states that the combustion front will act as a bulldozer, immediately mobilizing the oil ahead and reducing the air fingering. Hence, ignition is one of the critical aspects of AIP. In particular, the feasibility of spontaneous ignition is extremely important to the success of HPAI projects.

It is known that crude oil will oxidize when coming into contact with air and will generate heat by an LTO (low temperature oxidation) reaction. Although the exothermic rate of an LTO reaction is milder than that of an HTO (high-temperature oxidation) reaction, if the exothermic rate is greater than the heat loss rate, the temperature will rise and eventually reach ignition. In addition, most chemical reaction rates increase exponentially with the temperature, while the heat loss process only increases linearly; so it is feasible to transfer from an LTO reaction to a spontaneous combustion [5]. However, no laboratory experiments were reported on the detection of crude oil spontaneous ignition during AIP. A series of air flooding tests were performed by Abu-Khamsin et al. to study the potential of spontaneous ignition [6]. At the beginning of the experiments, sand was packed in the reactor, and the fluid (oil and brine) was then saturated. The oven was used to provide a reservoir temperature for the sand pack, and the thermocouples were placed in the sand pack to record the temperature profile. 22 experiments were run in total under different circumstances related to fluid saturations, pressures, oxygen concentrations, the sand pack type, flow rates and reaction times. All tests failed to observe a spontaneous ignition, with the maximum temperature increment being only around $10^{\circ} \mathrm{C}$. The authors claimed that the reason for the ignition failure was excessive heat loss and lack of fuel. Jia et al. [7] developed a special device to detect the thermal effect, where full-sized core samples were used to simulate the air flooding process. The heat loss was controlled by using the heat resistant tape. The in-situ temperature was monitored by four thermocouples that were placed at four different locations of the core. The initial reservoir temperature was set at $80^{\circ} \mathrm{C}$, and the experiment was conducted under isothermal conditions. The results showed that the temperature rose from $80^{\circ} \mathrm{C}$ to $89^{\circ} \mathrm{C}$ after around 22.2 days and then decreased back to the initial temperature. The authors discussed that the failure of the spontaneous ignition was attributed to the imperfect adiabatic condition, as the metal probes attached on the core have a high thermal conductivity.

In addition, the conventional AIP test, which is known as the combustion tube test, is not designed to investigate the spontaneous ignition feasibility but to study the combustion front sustainability. In the combustion tube tests, heaters are used to develop an initial high temperature before introducing air. Not only were the core flooding experiments actively applied to study the spontaneous ignition potential, but significant research efforts were also made based on the thermal experiments: TGA, DSC, SBR (small batch reactor) and ARC (accelerated rate calorimetry), which require small sample sizes and can be performed within a short period. Some researchers tend to call the thermal experiments screening tools, since the original intention of the thermal experiments is to select candidate oil for AIP implementation. However, most of the thermal tools are applied to study the crude oil's thermo-oxidative characteristics and to estimate the relevant oxidation reaction kinetic data for the kinetic model development during numerical simulation [8]. Hence, the way to determine the feasibility of spontaneous ignition based on thermal tools still needs to be answered.

This paper presents a practical method to determine the spontaneous ignition feasibility during AIP based on the kinetic data and reservoir thickness and temperature. This is the first time the Frank-Kamenetskii method has been employed to investigate the screening criteria for spontaneous ignition during AIP. This study can help researchers understand and determine the feasibility of spontaneous ignition based on the kinetic data obtained from thermal experiments. This study can 
also provide insights to researchers when designing experiments to investigate spontaneous ignition during AIP.

\section{Methodology}

\subsection{Spontaneous Ignition Theory}

Spontaneous ignition is a type of combustion that occurs through self-heating, followed by thermal runaway and, eventually, spontaneous ignition. Much research has been done on the spontaneous ignition of coal to prevent mine fire, which could endanger life, and which causes serious environmental pollution and economic losses $[9,10]$. Recent studies indicate that carbon rich rock, which contains significant amounts of organic matter, could also experience spontaneous ignition [11,12]. As stated previously, the heat loss processes usually increase linearly with the temperature increment, while the heat generation of chemical reactions increases almost exponentially. Thus, it is feasible to achieve spontaneous ignition based on the crude oil LTO exothermicity during AIP. For a combustible sample with a certain geometry, the amount of heat release is proportional to the sample's volume, and the volumetric heat loss is proportional to the sample's surface area. The critical ambient temperature indicates the minimum temperature for which the spontaneous ignition occurs. Hence, the critical ambient temperature for a spontaneous ignition decreases with the increments of the sample's size [5]. Since measuring the spontaneous ignition of a large combustible sample is difficult as it requires a large experimental space, complicated test conditions and long test periods. The traditional methods used to investigate spontaneous ignition rely on a scaling relation known as the Frank-Kamenetskii method, which is described in the following section.

\subsection{Application of the Frank-Kamenetskii Theory}

Despite the rapid development of the numerical simulation techniques, it is still far from trivial to develop satisfied finite element computation meshes for 3-D shapes. Therefore, the analytical method is still extensively used by researchers. The Frank-Kamenetskii theory has been extensively practiced to investigate spontaneous ignition, in particular to forecast spontaneous ignition for larger-sized samples at a low temperature environment when the exothermic mechanism is unchanged $[5,13]$. The Frank-Kamenetskii theory assumes that the sample is reactive and that the heat generation is based on a single-step chemical reaction. The theory can be described by the following equation:

$$
k \nabla^{2} T+Q f\left(c_{o}\right) e^{-E / R T}=0
$$

where $T_{\mathrm{a}}$ is the ambient temperature of the surroundings, with the boundary condition $T=T_{\mathrm{a}}$ on the walls of the body, $K ; E$ is the activation energy of the reaction, $\mathrm{J} / \mathrm{mole} ; k$ is the conductivity of the fuel, $\mathrm{W} /(\mathrm{m} \times \mathrm{K}) ; R$ is the universal gas constant, $8.314 \mathrm{~J} /($ mole $\cdot \mathrm{K}) ; Q$ is the heat of reaction per fuel mass, $\mathrm{W} / \mathrm{m}^{3}$; and $f\left(c_{0}\right)$ is the value of the mass action law which equals to the product of the reaction rate of the sample and the concentration of the sample, $\mathrm{mole} /\left(\mathrm{m}^{3} \cdot \mathrm{s}\right)$. In order to solve Equation (1) analytically, the dimensionless parameter $\delta$ is defined as:

$$
\delta=\frac{Q E f L^{2} e^{\left(-E / R T_{a}\right)}}{k R T_{a}^{2}}
$$

where $L$ is one half of the smallest dimension of the body, $m$. With the definition of $\delta$, Equation (1) can be solved at a steady state, and the following dependence of critical size and temperature is obtained, as shown below:

$$
\ln \left(\frac{\delta_{\text {critical }} T_{a, \text { critical }}^{2}}{L^{2}}\right)=\ln \left[\frac{Q E f\left(c_{o}\right)}{R k}\right]-E / R T_{a, \text { critical }}
$$


where $\delta_{\text {critical }}$ is the critical value of the dimensionless parameter in Equation (2), which relates the geometrical shape of the sample to the critical ambient temperature $T_{a, \text { critical }}$. An infinite slab geometry is assumed to be an oil reservoir, where $\delta_{\text {critical }}$ equals to 0.878 [5]. Hence, a plot of $\ln \left(\frac{\delta_{\text {critical }} T_{a, c r i t i c a l}^{2}}{L^{2}}\right)$ against $1 / T_{a, \text { critical }}$ will be straight line with a slope of $-E / R$ and intercept $\ln \left[\frac{Q E f\left(c_{0}\right)}{R k}\right]$.

This method can be used to obtain the activation energy when the critical temperature and critical size are measured from the experimental work. On the other hand, this method can also be used as a scaling law to predict the critical ambient temperature for large scale bodies from small laboratory samples, where $L$ is considered as the argument in Equation (3). Hence the equation can be used to estimate the critical size $L$ for a certain geometry $\delta_{\text {critical }}$ at the critical ambient temperature $T_{a, \text { critical }}$. In this way, parameters such as the reaction rate, activation energy and heat of the reaction, need to be provided. Hence, the TGA and DSC are employed in this study, where the TGA is used to obtain crude oil's kinetic data during oxidation reactions by applying the Arrhenius method, and the DSC is used to estimate the heat of the reaction.

However, since the samples used in TGA and DSC are very small, there are no thermal variations across the sample like there are in the ones in the field size reservoirs. Therefore, the proposed method in this study is only used for a qualitative screening study rather than a precise study. In other words, the purpose of this study is not to prove the existence of spontaneous ignition but to screen out the ones that cannot achieve spontaneous ignition. Furthermore, since the Arrhenius method is adopted to obtain the kinetic data of crude oil, the proposed method is highly sensitive to the assumptions of reaction chemistry. The details of the experimental work will be described in the following section.

\subsection{Experimental Method and Kinetic Theory}

\subsubsection{Experimental Method}

The TGA test is conducted (Figure 1) with the crude oil's mass variation being recorded during each experiment. The TGA balance can provide a microgram resolution, which is suitable for small samples. The sample size used in the TGA tests is around $5 \sim 15 \mathrm{mg}$. The sample chamber is sealed inside the furnace to control the sample's surrounding atmosphere. The active part of the chamber is made of fused silica, and various gasses can be selected as the reactive gas for the tested sample. To study the crude oil oxidation characteristics, the air is usually selected as the reactive gas, where a constant heating rate is applied during the tests. In most of the crude oil's air purging tests, two sudden mass losses are usually observed in the TGA results [14-16]. It was stated that the two mass loss behaviors imply the LTO and HTO, respectively. A relatively insignificant mass loss stage usually appears between the LTO and HTO stages, which implies the FD (fuel deposition) stage. Based on the TGA results, the corresponding kinetic data (activation energy and frequency factor) can be obtained. On the other hand, the DSC is widely used to study the exothermic or endothermic behavior of different substances. To investigate the AIP, the DSC is often conducted to investigate the exothermic activity of the crude oil sample and to obtain the heat generation of the crude oil oxidation reaction. Similar to the TGA experiment, the DSC tests are usually conducted under a certain heating rate, where the temperature increases linearly in relation to the time. Hence, the sample's net heat, which is known as the enthalpy, can be estimated based on the area of the exothermic DSC region, since the y axis of a DSC curve shows the heat flow of the oxidation reaction, and the $\mathrm{x}$ axis indicates the temperature. In addition, it was stated that in order to estimate the effective enthalpy value of a certain reaction interval, both the $\mathrm{N}_{2}$ and air purging DSC tests should be performed, where the nitrogen purging test is used to provide a base line that reflects only the endothermic behavior of the distillation process. More details about how to find the effective enthalpy value can be found in [17]. 


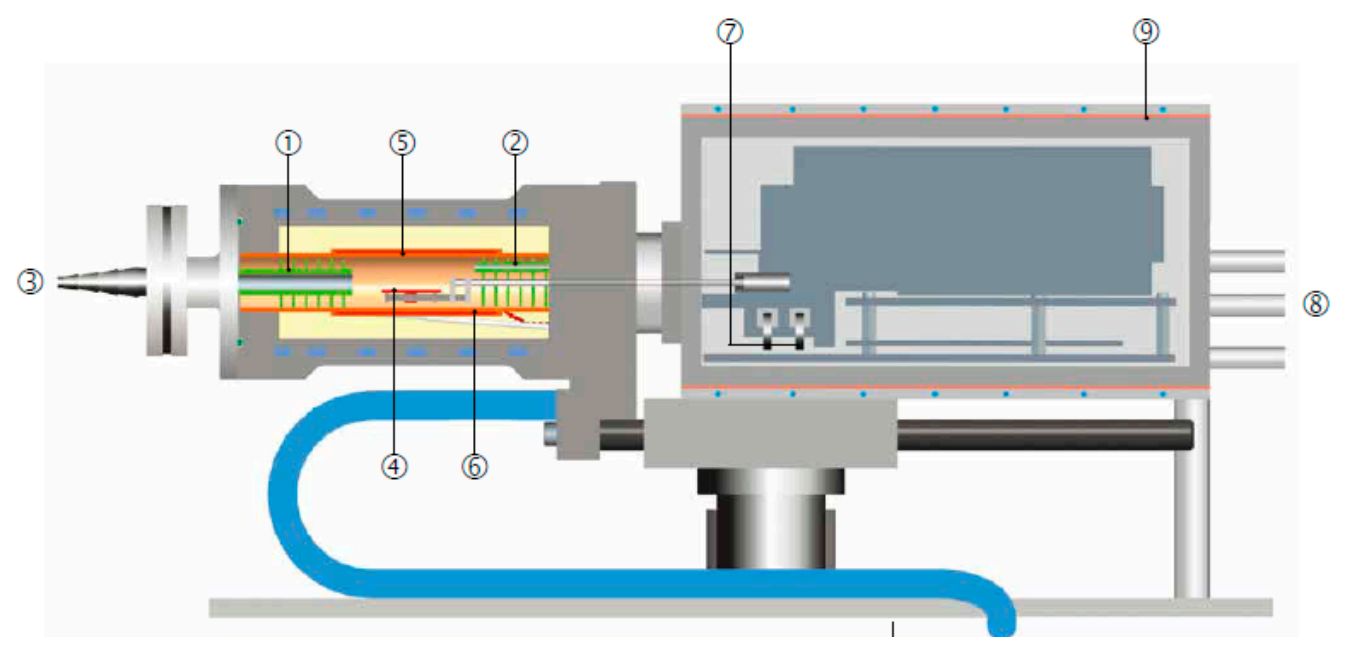

Figure 1. TGA and DSC (1: heat filter; 2: reaction gas capillary; 3: gas outlet; 4: temperature sensor; 5: furnace heating plate; 6: temperature sensor; 7: weight calibration; 8: gas connection port; and 9: thermostat balance room).

\subsubsection{Kinetic Theory}

The kinetic study of thermal decomposition has been the subject of interest to many researchers in the recent decades [18-22]. The Arrhenius method has been extensively applied to obtain the kinetic data based on the TGA results [8]. In the TGA experiments, since the sample size of crude oil is small and surrounded by excessive airflow, the oxidation process is assumed to be independent of oxygen concentration. Furthermore, it is pointed out that the oxidation reaction of crude oil is a first-order reaction to crude oil and is not restricted by mass transfer conditions [23]. As a result, kinetic data such as activation energy and frequency factor can be obtained by linear regression, where activation energy can be obtained by slope and frequency factor by intercept. The details about the transformation of Arrhenius equation and how to perform linear regression for TGA results are described in detail in Ref. [14], and the final transformed equation is presented as Equation (4).

$$
\ln \left(\frac{1}{(1-\alpha)^{n}} * \frac{d \alpha}{d T}\right)=\ln \left(\frac{f}{\beta}\right)-\frac{E}{R T}
$$

where the $\alpha$ stands for the degree of conversion and is a normalized form of weight loss of the decomposed sample; and $\beta$ is heating rates, ${ }^{\circ} \mathrm{C} / \mathrm{min}$. It is easy to find out that the plot of $\ln \left(\frac{1}{(1-\alpha)^{n}} * \frac{d \alpha}{d T}\right)$ against $1 / T$ will be a straight line with slope of $\mathrm{E} / \mathrm{R}$ and intercept of $\ln \left(\frac{f}{\beta}\right)$.

\section{Application of the Proposed Method}

\subsection{Experiment and Kinetic Analysis of a Mixture of Sand with Crude Oil}

The oil sample viscosity is $3 \mathrm{cp}$ at $25^{\circ} \mathrm{C}$, and the oil sample API is $40^{\circ}$ API. The composition of the crude oil was analyzed by GC (gas chromatography), and the carbon number distribution of this oil is shown in Figure 2. To save space, the detailed GC analysis procedure can be found in [24]. The sand was screened through a 50 mesh size in order to mix well with the crude oil. The weight ratio of oil to sand was prepared at 1 to 2 . The oil and sand were blended together in a glass tube, and the tube was then moved to the ultrasonic oscillators for thorough mixing. The TGA (TGA/SDTA851e Module) was employed in this study, where the TGA results were processed by STAR ${ }^{\mathrm{e}}$ software. All tests were carried out under air purging condition with a flow rate of $50 \mathrm{~mL} / \mathrm{min}$. In this study, the TGA heating rate was set at $10{ }^{\circ} \mathrm{C} / \mathrm{min}$, and the heating program was set at $25^{\circ} \mathrm{C}$ to $350{ }^{\circ} \mathrm{C}$, since the main objective was to investigate the spontaneous ignition of crude oil, which was mainly caused by the 
LTO exothermicity [17]. The tests were performed under atmospheric pressure and all the tests were repeated twice.

Figure 3 shows the air purging TGA and DTG (differential thermogravimetry) curves of the mixture of sand with oil under a heating rate of $10^{\circ} \mathrm{C} / \mathrm{min}$, where the DTG stands for the mass loss rate along with the temperature increment. It is noteworthy that the TGA curve in Figure 3 only reflects the normalized mass remaining from the oil sample, where it is assumed that no mass loss will occur to the sands under $350^{\circ} \mathrm{C}$. For the DTG curve, it is observed that the curve starts with a sudden decrease, and two valleys are presented. The first valley appears at $25^{\circ} \mathrm{C}$ to $190^{\circ} \mathrm{C}$ and the second valley occurs between $190^{\circ} \mathrm{C}$ and $350^{\circ} \mathrm{C}$. The first valley is dominated by the distillation process, and the second valley implies the LTO reactions. Therefore, the data in the LTO region was extracted and analyzed through the Arrhenius method, as shown in Equation (4). The kinetic data for the mixture of sand with oil was then obtained with an activation energy of $68.53 \mathrm{~kJ} / \mathrm{mole}$ and frequency factor of $8.63 \times 10^{4} \mathrm{~s}^{-1}$.

Figure 4 presents the DSC profiles of the mixture of oil and sand under air purging and nitrogen purging, respectively. It was seen that the nitrogen purging test shows an endothermic characteristic from $25^{\circ} \mathrm{C}$ to $350^{\circ} \mathrm{C}$, which is caused by the distillation. The air purging test for the mixture of oil and sand presented a milder endothermic behavior than the nitrogen purging before around $265^{\circ} \mathrm{C}$ and became exothermic after this point. The effective heat flow of the oxidation reactions was obtained by subtracting the DSC data of the nitrogen purging from the DSC data of the air purging, and the area of this subtracted curve, the shaded area, presents the enthalpy of the LTO reactions in this temperature interval. The area was obtained by integrating the subtracted DSC curve with the temperature, and the enthalpy value in this region was obtained as $6040 \mathrm{~J} / \mathrm{g}$.

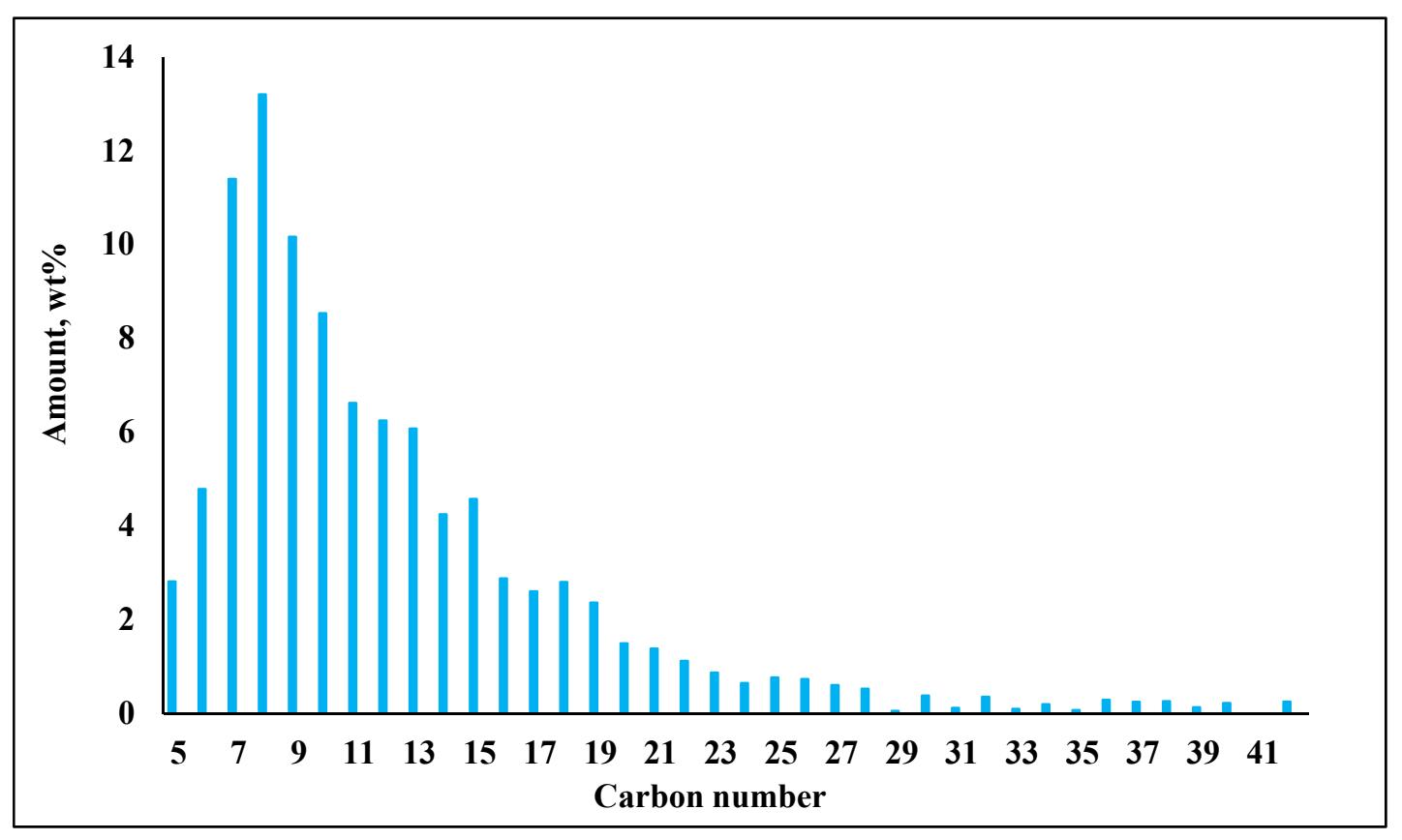

Figure 2. Carbon number distribution of crude oil. 


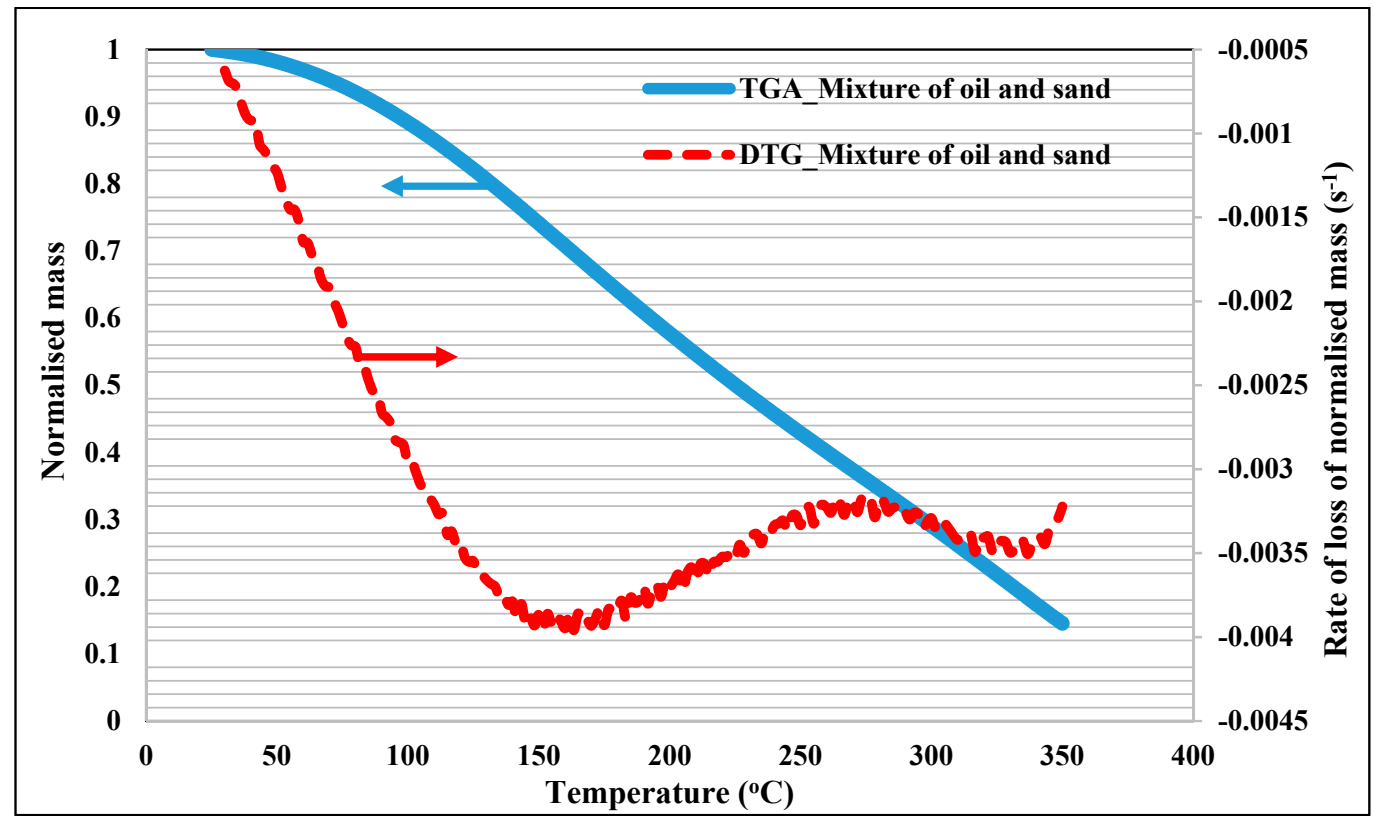

Figure 3. The TG and DTG results of the mixture of oil and sand (Heating rate $=10^{\circ} \mathrm{C} / \mathrm{min}$ ).

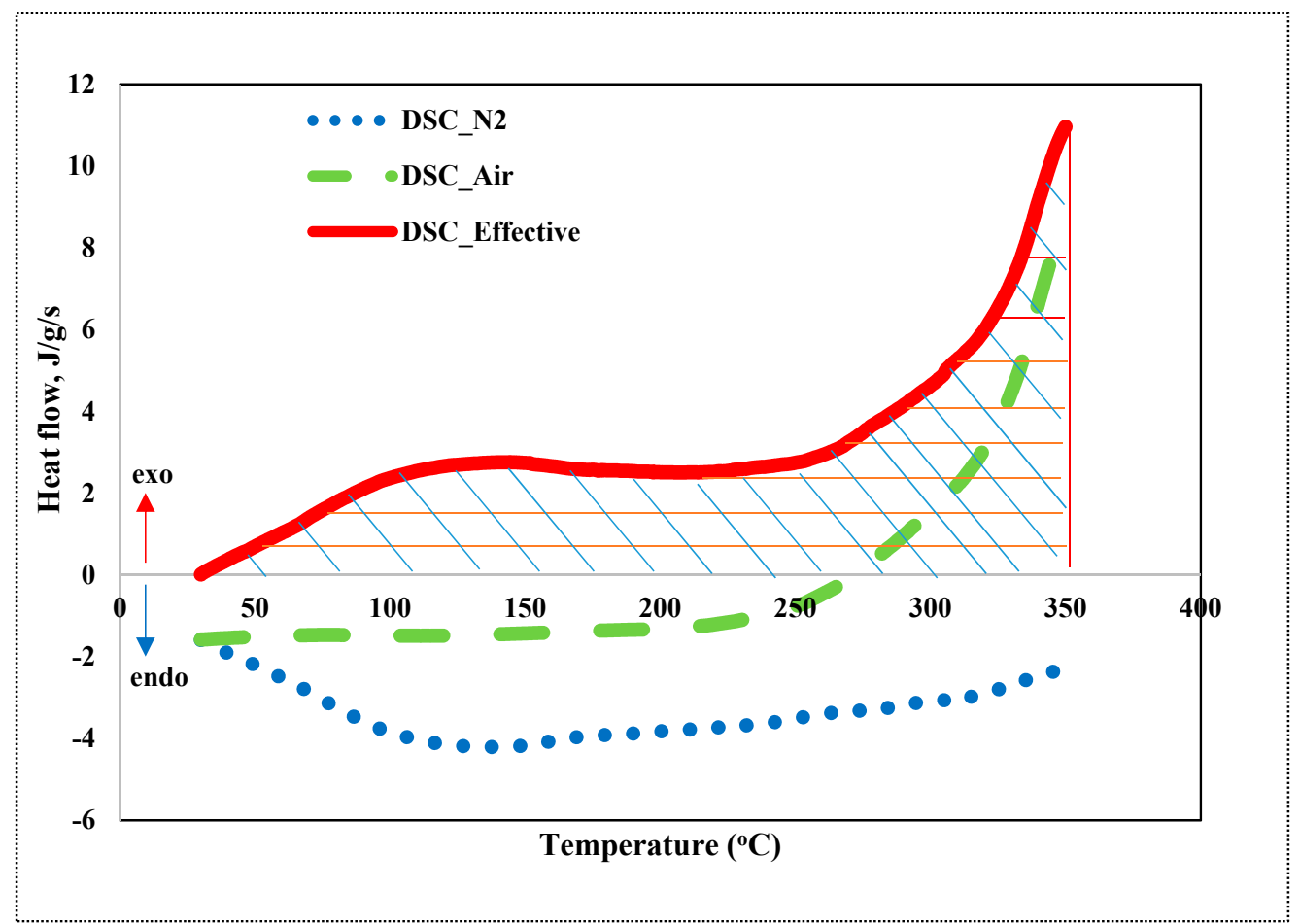

Figure 4. The DSC results of the mixture of oil and sand (Heating rate $=10^{\circ} \mathrm{C} / \mathrm{min}$ ).

\subsection{Spontaneous Ignition Feasibility by the Frank-Kamenetskii Method}

As mentioned previously, the oil reservoir can be modeled as an infinite slab because the reservoir thickness is much smaller than the width and length of the reservoir. Hence, the critical dimensionless parameter $\delta_{\text {critical }}=0.878$ is used in this study. After obtaining the kinetic data and enthalpy value, the properties listed in Table 1 are used in the Frank-Kamenetskii method to investigate the reservoir screening criteria for spontaneous ignition, and the result is presented in Figure 5. Figure 5 shows that the critical reservoir temperature for spontaneous ignition decreases with the increments of the reservoir thickness. In particular, the reservoir thicknesses that are feasible for spontaneous ignition at typical oil reservoir temperatures of $70{ }^{\circ} \mathrm{C}$ to $140{ }^{\circ} \mathrm{C}$ are indicated in Figure 5. The results show 
that at $70{ }^{\circ} \mathrm{C}$ the oil reservoir can be spontaneously ignited with a minimum reservoir thickness of $391 \mathrm{~m}$. As the reservoir temperature increases to $140{ }^{\circ} \mathrm{C}$, the minimum reservoir thickness required for spontaneous ignition decreases to $84 \mathrm{~m}$. Although the oil formation thickness varies from $2 \mathrm{~m}$ to $100 \mathrm{~m}$, most of the individual oil layer thickness varies between $1 \mathrm{~m}$ and $30 \mathrm{~m}$ [25]. Based on the typical reservoir temperature and typical oil layer thickness, the possible reservoir environments are marked as the shaded area in Figure 5, which reveals that the spontaneous ignition for this tested oil cannot be feasibly achieved since the result curve lies outside the shaded zone.

Since the frequency factor obtained from the thermal experiments is based on the intercept of a log axis, it is very sensible to interpret the thermograms when selecting the slope. Hence, the effects of the typical frequency factor value of the LTO reaction with a magnitude of $1.0 \times 10^{-1} \mathrm{~s}^{-1}$ to $1.0 \times 10^{5} \mathrm{~s}^{-1}$ crude oil were tested [8]. As presented in Figure 5, a lower frequency factor requires a thicker reservoir thickness to achieve spontaneous ignition at the same reservoir temperature. When using the highest frequency factor of $8.63 \times 10^{5}$ at a reservoir temperature of $140^{\circ} \mathrm{C}$, the required minimum reservoir thickness for spontaneous ignition is $26 \mathrm{~m}$, which is possible for a real situation.

The application presented in this section not only shows the spontaneous ignition feasibility for this tested crude oil, but also illustrates that the Frank-Kamenetskii method can be used as an effective method to screen the crude oil for AIP in terms of spontaneous ignition feasibility. When applying this method, it should be noted that the net heat value used in Equation (3) is obtained by the DSC of the corresponding temperature interval. In other words, it is assumed that the thermal energy can accumulate and raise the temperature to complete the entire reaction. In addition, the Frank-Kamenetskii method assumes that the oxygen and reactants are sufficient for the exothermic reaction to take place. Therefore, the proposed method in this study is only used for a qualitative screening study rather than a precise study. When screening suitable crude oil for HPAI with this method, the crude oil that cannot achieve spontaneous ignition should be screened out, and the crude oil that can achieve spontaneous ignition should be further evaluated via field pilot tests.

Table 1. The properties of the mixture of sand and oil.

\begin{tabular}{ccccccc}
\hline$\delta_{\text {critical }}$ & $\mathbf{f}$ & $\frac{\rho}{M W}$ & $\mathbf{f}(\mathbf{c o})=f \times\left(\frac{\rho}{M W}\right)$ & $\mathbf{k}$ & $\mathbf{Q}$ & $\mathbf{E}$ \\
\hline$/$ & $1 / \mathrm{s}$ & $\mathrm{mole} / \mathrm{m}^{3}$ & $\mathrm{~mole} /\left(\mathrm{m}^{3} \times \mathrm{s}\right)$ & $\mathrm{W} /(\mathrm{m} \times \mathrm{K})$ & $\mathrm{kJ} / \mathrm{kg}$ & $\mathrm{kJ} / \mathrm{mole}$ \\
\hline 0.878 & 86,300 & 4.736 & 408,685 & 0.5 & 6040 & 69 \\
\hline
\end{tabular}

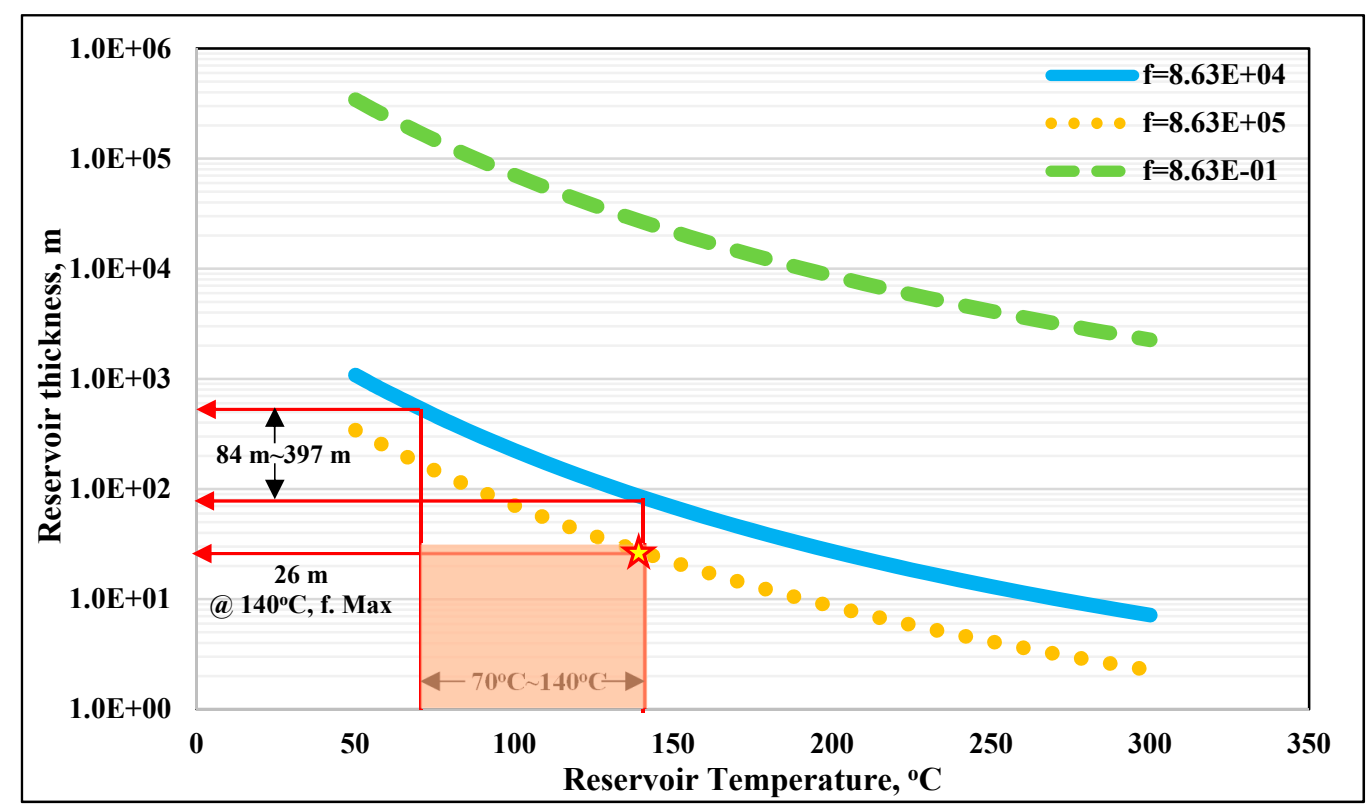

Figure 5. The spontaneous ignition screening criteria for the tested mixture of oil and sand. 


\section{Discussion of Screening Criteria for Spontaneous Ignition during AIP}

The original intention for the thermal experiments was to select candidate oil for AIP in a more efficient and less expensive way than combustion tube tests. However, instead of performing a feasibility study, most of the research only employed thermal experiments as a tool to obtain kinetic data and characterize the thermal-oxidative behavior for different crude oil samples. A comprehensive review of the screening criteria for AIP based on thermal experiments was performed by Huang and Sheng [8], where the screening criteria for AIP was summarized into the following aspects: (1) the crude oil should present a continuous heat release activity between the pre-combustion temperature and ignition temperature; (2) oil with a lower activation energy is more favorable for AIP; (3) oil that has a lower ignition temperature is more promising for AIP; (4) the longer and more stable the exothermic activity region is, the better the AIP effect is; and (5) oil that consumes more oxygen and generates more flue gas during the LTO stage is more favorable for AIP. The aforementioned screening criteria can be concluded in one sentence: a more reactive oil is more feasible for AIP. However, no quantitative method has been developed that can relate the oil reactivity to the AIP feasibility.

The typical crude oil kinetic data values were summarized by Huang and Sheng [8]. For the light oil LTO reaction, the typical value of activation energy ranges from $20 \mathrm{~kJ} / \mathrm{mole}$ to $70 \mathrm{~kJ} / \mathrm{mole}$, and the typical value for the frequency factor varies from $0.1 \mathrm{~s}^{-1}$ to $10^{5} \mathrm{~s}^{-1}$. Figure 6 shows the effect of the activation energy on the spontaneous ignition feasibility based on the properties listed in Table 2 and the max frequency factor of $10^{5} \mathrm{~s}^{-1}$. The shaded area in Figure 6 represents the possible reservoir conditions with temperatures between $70^{\circ} \mathrm{C}$ to $140{ }^{\circ} \mathrm{C}$ and a reservoir thickness between $1 \mathrm{~m}$ and $30 \mathrm{~m}$. It is observed that at a certain temperature, a lower activation energy requires a thinner reservoir thickness to achieve spontaneous ignition. The star mark located at the top right corner of the shaded area indicates the critical conditions for spontaneous ignition. It can be seen that at an activation energy of $60 \mathrm{~kJ} / \mathrm{mole}$, the critical line just intercepts with the shaded area. Since the max frequency factor was used for all the calculations, if the activation energy of crude oil cannot meet the spontaneous ignition criteria, this shows that it is impossible for the crude oil to achieve spontaneous ignition. Therefore, according to Figure 6, the critical crude oil activation energy (max) required for spontaneous ignition is $60 \mathrm{~kJ} / \mathrm{mole}$.

Table 2. The properties used for the spontaneous ignition sensitivity analysis.

\begin{tabular}{ccccc}
\hline$\delta_{\text {critical }}$ & $\frac{\rho}{M W}$ & $\mathbf{k}$ & $\mathbf{Q}$ & $\mathbf{E}$ \\
\hline$/$ & $\mathrm{mole} / \mathrm{m}^{3}$ & $\mathrm{~W} /(\mathrm{m} \times \mathrm{K})$ & $\mathrm{kJ} / \mathrm{kg}$ & $\mathrm{kJ} / \mathrm{mole}$ \\
\hline 0.878 & 4.736 & 0.5 & 6040 & 69 \\
\hline
\end{tabular}

A similar approach was also applied to investigate the critical crude oil frequency factor for spontaneous ignition, where the properties listed in Table 2 and the minimum activation energy of $20 \mathrm{~kJ} / \mathrm{mole}$ were used. The results show that, at a certain temperature condition, a higher frequency factor requires a thinner reservoir thickness for spontaneous ignition. Similar to the previous practice, at a possible reservoir condition with a temperature between $70^{\circ} \mathrm{C}$ and $140{ }^{\circ} \mathrm{C}$ and a reservoir thickness between $1 \mathrm{~m}$ and $30 \mathrm{~m}$, the critical frequency factor (minimum) required to achieve spontaneous ignition is $2 \mathrm{~s}^{-1}$, as the critical line of the frequency factor is at $2 \mathrm{~s}^{-1}$.

To sum up, at the possible reservoir conditions where the temperature is between $70{ }^{\circ} \mathrm{C} \sim 140{ }^{\circ} \mathrm{C}$ and the reservoir thickness is between $1 \mathrm{~m} \sim 30 \mathrm{~m}$, in order to achieve spontaneous ignition the activation energy should be less than $60 \mathrm{~kJ} / \mathrm{mole}$, and the frequency factor should be greater than $2 \mathrm{~s}^{-1}$. 


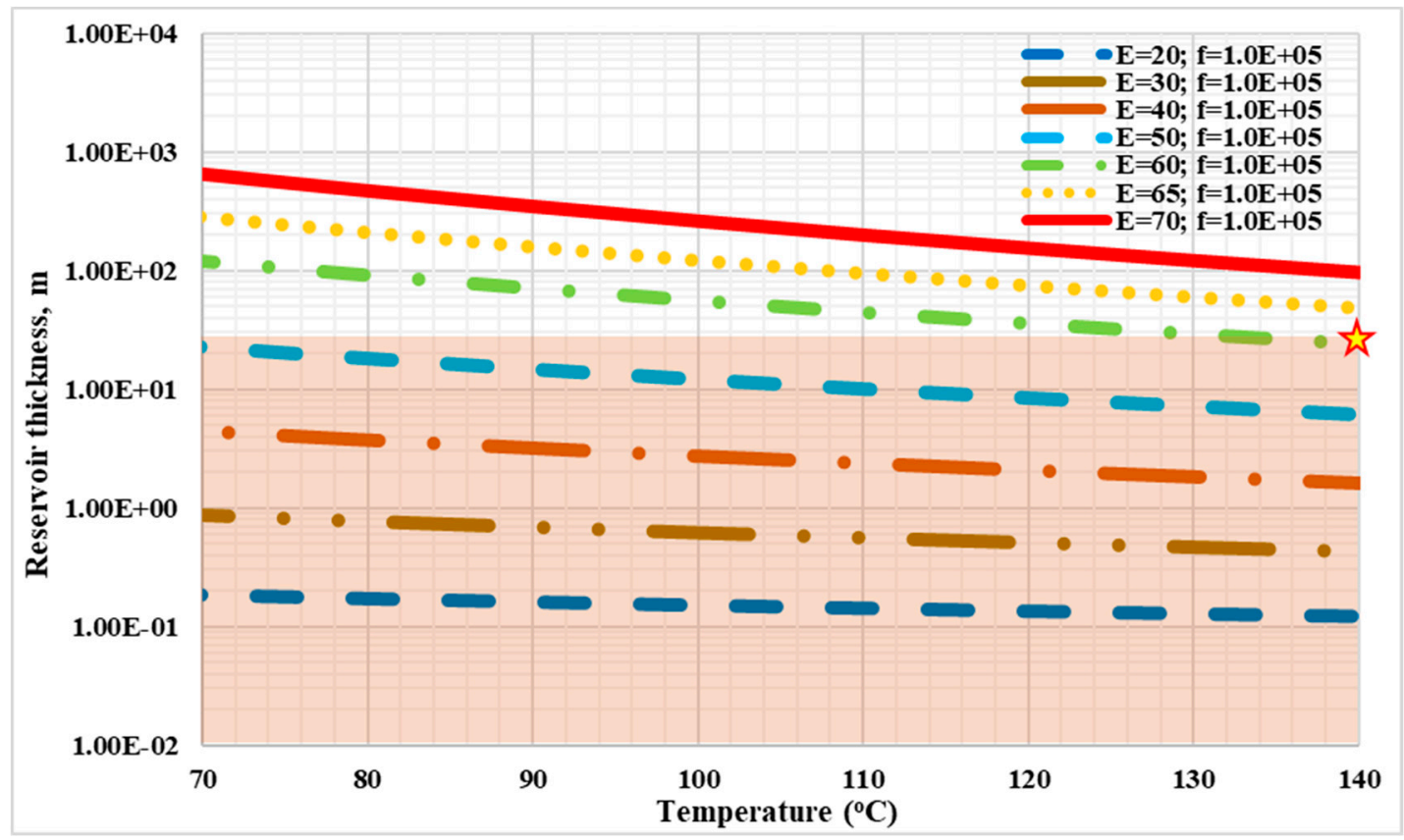

Figure 6. The effect of the critical activation energy of crude oil on spontaneous ignition.

\section{Conclusions}

This paper presents a practical method to determine the spontaneous ignition feasibility during AIP based on the kinetic data and reservoir thickness and temperature. This study can help researchers understand and determine the feasibility of spontaneous ignition based on kinetic data obtained from thermal experiments. This study can also provide insights to researchers in terms of designing experiments to investigate spontaneous ignition during AIP. Based on this study, the following conclusions may be drawn:

> The Frank-Kamenetskii method can be applied as an effective method to screen crude oil for AIP in terms of spontaneous ignition feasibility, based on thermal experiments such as TGA and DSC.

$>$ The proposed method could screen out the mixture of oil and sand that cannot achieve spontaneous ignition due to an insufficient reactivity. However, if the tested sample shows the potential to achieve spontaneous ignition, further experiments need to be applied in order to prove the existence of spontaneous ignition.

$>$ At a possible reservoir condition with a temperature from $70^{\circ} \mathrm{C}$ to $140^{\circ} \mathrm{C}$ and a reservoir thickness from $1 \mathrm{~m}$ to $30 \mathrm{~m}$, in order to achieve spontaneous ignition for an AIP the activation energy of the crude oil should be less than $60 \mathrm{~kJ} / \mathrm{mole}$, and the frequency factor should be greater than $2 \mathrm{~s}^{-1}$.

Author Contributions: Writing—original draft, S.H.; Writing—review \& editing, J.J.S. and Q.J. Validation, J.L.

Funding: This work is funded by the Science \& Technology Department of Sichuan Province under Award No. 2018FZ0070.

Conflicts of Interest: The authors declare no conflict of interest.

\section{Nomenclature}

$\alpha \quad$ Fractional conversion

$\beta \quad$ Heating rate, $\mathrm{k} / \mathrm{min}$

A Arrhenius constant, $\mathrm{min}^{-1}$

E Activation energy, $\mathrm{J} / \mathrm{mol}$

$f\left(c_{0}\right) \quad$ value of the mass action law, mole $/\left(\mathrm{m}^{3} \cdot \mathrm{s}\right)$

$\mathrm{H} \quad$ The fraction of the enthalpy yet to be released, $\mathrm{kJ}$ 
k Temperature dependent rate constant.

$L \quad$ one half of the smallest dimension of the body, $\mathrm{m}$

$\mathrm{m}_{\mathrm{i}} \quad$ Initial mass of the sample, $\mathrm{mg}$.

$\mathrm{m}_{\mathrm{f}} \quad$ The final mass of the sample, $\mathrm{mg}$.

$\mathrm{m}_{\mathrm{t}} \quad$ The sample mass at temperature $\mathrm{T}, \mathrm{mg}$.

$\mathrm{n}$ The order of reaction.

$Q \quad$ heat of reaction per fuel mass, $\mathrm{W} / \mathrm{m}^{3}$

$R \quad$ Gas constant, $8.314 \mathrm{~J} / \mathrm{mol} \mathrm{K}$

$T_{p} \quad$ Peak temperature, $\mathrm{K}$

$T_{a} \quad$ Ambient temperature, $\mathrm{K}$.

$\mathrm{Z} \quad$ Pre-exponential factor, $1 / \mathrm{s}$.

\section{References}

1. Kumar, V.K.; Gutierrez, D.; Moore, R.G.; Mehta, S.A. Case history and appraisal of the West Buffalo Red River Unit high-pressure air injection project. In Proceedings of the Hydrocarbon Economics and Evaluation Symposium, Paper SPE 107715, Dallas, TX, USA, 1-3 April 2007; pp. 1-3.

2. Gutiérrez, D.; Miller, R.J.; Taylor, A.R.; Thies, B.P.; Kumar, V.K. Buffalo Field High-Pressure Air Injection Projects: Technical Performance and Operational Challenges (SPE-113254). In Proceedings of the SPE/DOE Symposium on Improved Oil Recovery, Tulsa, OK, USA, 19-23 April 2008; pp. 20-23.

3. Gates, C.F.; Ramey , H.J., Jr. Field results of south belridge thermal recovery experiment. J. Petroleum Technol. 1958, 213, 236-244.

4. Gutierrez, D.; Skoreyko, F.; Moore, R.G.; Mehta, S.A.; Ursenbach, M.G. The challenge of predicting field performance of air injection projects based on laboratory and numerical modelling. J. Can. Pet. Technol. 2009, 48, 23-33. [CrossRef]

5. Gray, B.F. Spontaneous combustion and self-heating. In SFPE Handbook of Fire Protection Engineering; Springer: New York, NY, USA, 2016; pp. 604-632.

6. Abu-Khamsin, S.A.; Iddris, A.; Aggour, M.A. The spontaneous ignition potential of a super-light crude oil. Fuel 2001, 80, 1415-1420. [CrossRef]

7. Jia, H.; Zhao, J.Z.; Pu, W.F.; Li, Y.M.; Yuan, Z.T.; Yuan, C.D. Laboratory investigation on the feasibility of light-oil autoignition for application of the high-pressure air injection (HPAI) process. Energy Fuels 2012, 26, 5638-5645. [CrossRef]

8. Huang, S.; Sheng, J.J. Discussion of thermal experiments' capability to screen the feasibility of air injection. Fuel 2017, 195, 151-164. [CrossRef]

9. Stracher, G.B.; Taylor, T.P. Coal fires burning out of control around the world: Thermodynamic recipe for environmental catastrophe. Int. J. Coal Geol. 2004, 59, 7-17. [CrossRef]

10. Wang, Y.; Zhang, X.; Sugai, Y.; Sasaki, K. Determination of critical self-ignition temperature of low-rank coal using a $1 \mathrm{~m}$ wire-mesh basket and extrapolation to industrial coal piles. Energy Fuels 2017, 31, 6700-6710. [CrossRef]

11. Restuccia, F.; Huang, X.; Rein, G. Self-ignition of natural fuels: Can wildfires of carbon-rich soil start by self-heating? Fire Saf. J. 2017, 91, 828-834. [CrossRef]

12. Restuccia, F.; Ptak, N.; Rein, G. Self-heating behavior and ignition of shale rock. Combust. Flame 2017, 176, 213-219. [CrossRef]

13. Drysdale, D. An Introduction to Fire Dynamics; John Wiley \& Sons: Hoboken, NJ, USA, 2011.

14. Huang, S.; Jia, H.; Sheng, J.J. Research on oxidation kinetics of tight oil from Wolfcamp field. Pet. Sci. Technol. 2016, 34, 903-910. [CrossRef]

15. Huang, S.; Jia, H.; Sheng, J.J. Effect of shale core on combustion reactions of tight oil from Wolfcamp reservoir. Pet. Sci. Technol. 2016, 34, 1172-1179. [CrossRef]

16. Huang, S.; Jia, H.; Sheng, J.J. Exothermicity and oxidation behavior of tight oil with cuttings from the Wolfcamp shale reservoir. Pet. Sci. Technol. 2016, 34, 1735-1741. [CrossRef]

17. Huang, S.; Sheng, J.J. An innovative method to build a comprehensive kinetic model for air injection using TGA/DSC experiments. Fuel 2017, 210, 98-106. [CrossRef] 
18. Jia, H.; Ni, J.; Pu, W.; Yue, P.; Jiang, H.; Yang, J. New view on the oxidation mechanisms of crude oil through combined thermal analysis methods. J. Therm. Anal. Calorim. 2014, 118, 1707-1714. [CrossRef]

19. Jia, H.; Zhao, J.Z.; Pu, W.F.; Zhao, J.; Kuang, X.Y. Thermal study on light crude oil for application of high-pressure air injection (HPAI) process by TG/DTG and DTA tests. Energy Fuels 2012, 26, 1575-1584. [CrossRef]

20. Ren, S.R.; Greaves, M.; Rathbone, R.R. Oxidation kinetics of North Sea light crude oils at reservoir temperature. Chem. Eng. Res. Des. 1999, 77, 385-394. [CrossRef]

21. Hou, S.M.; Liu, Y.H.; Yu, H.M.; Niu, B.L.; Ren, S.R. Kinetics of low temperature oxidation of light oil in air injection process. J. China Univ. Pet. 2011, 35, 169-173.

22. Huang, S.; Sheng, J.J. A practical method to obtain kinetic data from TGA (thermogravimetric analysis) experiments to build an air injection model for enhanced oil recovery. Fuel 2017, 206, 199-209. [CrossRef]

23. Gundogar, A.S.; Kok, M.V. Thermal characterization, combustion and kinetics of different origin crude oils. Fuel 2014, 123, 59-65. [CrossRef]

24. Stadler, M.P.; Deo, M.D.; Orr, F.M., Jr. Crude oil characterization using gas chromatography and supercritical fluid chromatography. In Proceedings of the SPE International Symposium on Oilfield Chemistry, New Orleans, LA, USA, 2-5 March 1993.

25. Jia, H.; Sheng, J.J. Discussion of the feasibility of air injection for enhanced oil recovery in shale oil reservoirs. Petroleum 2017, 3, 249-257. [CrossRef]

(C) 2019 by the authors. Licensee MDPI, Basel, Switzerland. This article is an open access article distributed under the terms and conditions of the Creative Commons Attribution (CC BY) license (http://creativecommons.org/licenses/by/4.0/). 